\title{
Commentary Reluctant horses at the digital river
} John J Marini

Professor of Medicine, University of Minnesota

Correspondence: John J Marini, John.J.Marini@healthpartners.com

Published online: 25 August 2004

Critical Care 2004, 8:313-314 (DOI 10.1186/cc2942)

This article is online at http://ccforum.com/content/8/5/313

(c) 2004 BioMed Central Ltd

Related to Research by Martinez-Motta et al., see page 395

\begin{abstract}
Mastery of the changing bank of information needed to practice at the cutting edge will require the exploitation of emerging informatics and communication technologies. Whether their limitless promise will be embraced or forgone will depend as much on human as on technological practice.
\end{abstract}

Keywords communications, handheld computers, informatics, medical practice

The pace at which computer-enabled technologies transform our daily lives threatens to reshape our familiar world beyond recognition, even as it opens dramatic possibilities for advancing our personal and professional lives. In medicine, mastery of the changing information bank needed to practice at the cutting edge is achieved by the relative few who have the required time, dedication, resources, and access to technical aids. A compelling argument can be made that emerging informatics and communication technologies must be leveraged to make such a task manageable. The report by Martinez-Motta and colleagues [1] that appears in this issue of Critical Care illustrates that adoption of some useful applications of computer technology may run counter to ingrained behaviors that are conditioned by human nature. $A$ familiar adage seems applicable here: 'You can lead a horse to water, but you cannot make it drink.' Maybe not, but our incentives to sip from the raging digital river include both carrots and sticks.

Acceptance of innovative technology is a function of utility and accessibility, as well as attitude. Some might characterize physicians as atypically conservative and 'technophobic', but this stereotyping is a bit unfair and far from the full explanation. Apart from economic considerations, reticence in embracing the information age has been encouraged by the need for high 'front end' investment in learning, by unreliable hardware, by clumsy or unintuitive user interfaces, by 'buggy' software, and by poorly conceived applications with low inherent utility. To be adopted by the target audience, any device or algorithm must fulfill genuine needs and be relatively simple to use. Those relatively few products of the information age that meet those requirements have been greeted with widespread acceptance by all sectors of society exposed to them. Examples of such 'killer apps' for individual consumers include word processing, e-mail, mobile ('cellular') telephones, integrated internet portals (e.g. Yahoo $\left.{ }^{(}\right)$ [www.yahoo.com]), efficient search engines (e.g. Google ${ }^{\odot}$ [www.google.com]), digital photography, and digitized music. Certain applications not only facilitate tasks that could be carried out at a slower pace by alternative means but also enable activities that otherwise would be impossible to contemplate. The virtual marketplace offered by eBay ${ }^{\odot}$ (www.ebay.com), for example, makes awareness and commercial encounters possible in real time among myriad dispersed individuals that would be unthinkable without internet communication.

To be ignorant of the increasing need to do more with less implies that one has not been paying attention to the changes in our economically constrained medical environment. This imperative is a key metaphorical 'stick' driving us toward seeking help from informatics. What, then, are the benefits for critical care practice that might result from electronic information management? A partial listing of these 'electronic carrots' might include literature retrieval and 
distillation; limitless opportunity for self-education; ubiquitous access to accurate and appropriately indexed medical records; immediate, well timed communication among colleagues with varied skills and expertise; and easier documentation (e.g. by reliable electronic voice transcription and immediate wireless transfers to sites of need). Essential to all of these are timeliness, ease of use, and portability.

The personal digital assistant (PDA) - the subject of the report by Martinez-Motta and coworkers [1] - has become increasingly capable of fulfilling these functions. No longer a nifty gadget that simply offers a few useful applications and convenient storage for personal contact information, calendar and notes, the latest devices are powerful yet highly portable computers that incorporate wireless internet access, storage capacity for digital textbooks and other large medical databases, mobile telephony, and photographic capability. The functional lines between PDAs, personal computers, and mobile telephones are blurring into a unified portable platform. When securely interfaced to servers designed and programmed to facilitate transfer of medical information, such mobile devices have the potential to bring most elements of the information database quickly to bear on the management decisions as they are made at the bedside. The value of immediate accessibility to accurate information for education purposes and correct decision making should not be underestimated in a complex work environment in which outcome, economic, and legal premiums are determined by timely and decisive action. Thus, although still imperfect and falling a bit short of the quixotic goal of offering an all-in-one portable device that offers convergence of all essential for ubiquitous information and communication access, we are now only a short time away from having such capability.

If the promise of communication technology is impressive for advanced, urbanized medical environments, what they represent to underdeveloped, isolated, and underserved populations is no less than a dazzling jump over the digital divide that has separated us, with a promise for more equitable diffusion of health care. The overwhelming acceptance of mobile telephony in such societies is but one example of the potential for the transformation. Not only has the cost of acquiring and transmitting digital data plummeted, but steadily improving communication infrastructure and expanding bandwidth of easily accessed information channels allow rapid transfer of high-density data packets (such as images and voice) at minimal cost. Effective telemedical consulting has become affordable, even for the unscheduled or impromptu needs of individual patients who are far removed from the relevant expert. This flexibility is of great interest for small market and/or isolated populations that have few doctors of any kind and cannot support specialists in many important medical or surgical disciplines. In the majority of countries that are impoverished and/or geographically segmented, specialty care is available only in the few large cities that support the requisite referral base.
For critically ill patients who cannot easily be transported, timely access to specialist expertise may be life-saving. Even in the wealthiest countries, chronic electronic surveillance of mentally or physically debilitated patients may allow earlier intervention or assure compliance with complicated treatment regimens at home, improving the safety and costeffectiveness of their health care. Improved distribution of specialty expertise through electronic communication may also help ease the pressures of an aging population cared for by a limited number of qualified personnel. Ongoing experiments in 'centralized surveillance' by ICU trained personnel who care for patients in many hospitals but are concentrated at single sites have surfaced in a number of communities. Even more dramatic is the emerging capability for delicate surgical procedures to be performed with great precision utilizing computer-guided robotic control - even across great distances by experts who guide instruments attended by others via digital communications.

Despite these extraordinary prospects for technologyleveraged information management, numerous barriers first must be addressed. Of the technical, legal, economic, and acceptance roadblocks, the latter may prove among the most difficult to overcome. As the report by Martinez-Motta and coworkers [1] demonstrates, human factors often limit the adoption or effectiveness of promising technology - even in the most sophisticated urban medical centers. In this instance, the technology worked, was accessible, and the application was simple to understand. Perhaps failure to employ documentation technology consistently was explained by poor motivation, perceived lack of need, failure to repeatedly re-enforce the technical methods or mandate, or ingrained familiarity with workable - if inherently less efficient - alternatives to manage the data. Other applications with immediate and self re-enforcing payoff are likely to have encouraged better compliance. This lesson has already been learned with electronic education vehicles such as streamlined literature searching (e.g. PubMed [www.ncbi.nlm.nih.gov/entrez/query.fcgi]), informatics based medical texts (e.g. Up-To-Date ${ }^{\complement}$ [www.uptodate.com]), and point-of-care prescribing information (e.g. Epocrates ${ }^{\odot}$ [www.Epocrates.com]). Whether the limitless promise of other important applications of communications and computing technology will be embraced, deferred, or forgone will be determined by 'the human factor' as well as by technological and economic considerations.

\section{Competing interests}

The author declares that he has no competing interests.

\section{Reference}

1. Martinez-Motta JC, Walker R, Stewart TE, Granton J, Abrahamson S, Lapinsky SE: Critical care procedure logging using handheld computers. Crit Care 2004, 8:R336-R342. 